\title{
O DÂNDI DOS PAMPAS
}

\author{
Cesar Marcos Casaroto Filho \\ Doutorando em Letras (Teoria da Literatura) pela Pontifícia Universidade Católica do Rio \\ Grande do Sul (PUCRS) \\ cesarcasarotofilho@gmail.com
}

\section{RESUMO}

No presente artigo, tenho por objetivo definir o que denomino dândi dos pampas, o artista-intelectual que, vivendo com arte, por meio das suas payadas, resiste ao espírito do colonialismo. Sem negar as suas origens crioulas, o dândi dos pampas revolta-se contra o patronato ao sustentar a sua ética em versos. Ao estetizar a existência, o dândi dos pampas denuncia os abusos históricos sofridos pela América Latina. Para dar forma ao dândi dos pampas analisarei "Coplas del payador perseguido", de Atahualpa Yupanqui e "Payada", de Jayme Caetano Braun.

Palavras-chave: dândi dos pampas, payada, ética, revolução.

\section{RÉSUMÉ}

Dans cet article je veux definir ce que j'appelle dândi dos pampas, l'artisteintellectuel qui, en vivant comme une œuvre d'art, il résiste à l'esprit du colonialisme à travers ses payadas. Sans nier ses origines créoles, le dândi dos pampas se révolte contre le népotisme en affirmant son éthique en vers. En esthétisant son existence, le dândi dos pampas dénonce les abus historiques subis par l'Amérique Latine. Pour délimiter le dândi dos pampas j'analyserai "Coplas del payador perseguido" par Atahualpa Yupanqui et "Payada" par Jayme Caetano Braun.

Mots-clés: dândi dos pampas, payada, éthique, révolution. 


\section{O dândi dos pampas}

Partindo do princípio de que a figura do dândi não se restringe historicamente aos séculos XVIII e XIX, compreendo o dandismo como um fenômeno que, com o passar do tempo, na esteira da história vai adquirindo novas roupagens. Viso, com esse trabalho, deslocar a ideia de dândi enquanto intelectual cosmopolita', de modo a ampliar as possibilidades de análise de novos fenômenos-dândi em outros lugares do mundo, como na América Latina. Concordo, assim, com o excerto de Charles Baudelaire, presente em sua teoria sobre o dandismo:

o dandismo é uma instituição vaga, tão bizarra quanto o duelo; tão antiga, pois dela César, Catilina, Alcibíades nos dão exemplos impressionantes; tão geral, pois Chateaubriand descobre-a nas florestas e às margens dos lagos do Novo Mundo (2010, p. 62).

Porém, antes de analisar as payadas "Coplas del payador perseguido", de Athaualpa Yupanqui, e "Payada", de Jayme Caetano Braun, em cuja poesia procurarei delimitar a figura do que denomino dândi dos pampas, definirei o dândi. O dândi aqui será conceituado com a contribuição dos seguintes pensadores: Baudelaire, Friedrich Nietzsche e Michel Foucault. Para que se pense o dândi é necessário que se leve em conta principalmente termos como revolta, estetização da existência, revolução, pathos da distância, e, essencialmente, ética, êthos. Penso, desse modo, a seguinte forma para o dândi dos pampas: essencialmente solitário, o dândi dos pampas, por apresentar uma ética singular, eterno insurrecto, revoluciona a si mesmo e ao mundo ao desnudar os pampas com sua forma de vida poética. 
A ideia que faz Nietzsche (2016) sobre o ressentimento e suas implicações no plano moral merece ser esclarecida levando em consideração o princípio moral do "senhor", aquele que, mais forte, ao contrário do "escravo", ou "ressentido", utiliza das suas potencialidades criadoras para forjar-se enquanto sujeitoii. Contrapondo a moral do senhor à do escravo, afirma Nietzsche: "enquanto toda moral nobre brota de um triunfante Sim a si própria, a moral do escravo diz, desde o princípio, Não ao que é 'de fora', um 'outro', um 'não eu' - e esse Não é o seu ato criativo" (2016, p. 30). Ou seja, enquanto a moral nobre, própria do sujeito consciente de suas potencialidades, diz Sim à vida e à sua multiplicidade, o que resulta na procura por novas formas de vida possíveis, a moral do escravo, restrita ao Não, fecha o dinamismo da vida e as suas cambiantes variações. Poderia aqui opor o princípio artístico à moral burguesa. Ao passo que o artista, aberto à fantasia, explora necessariamente existências por meio de uma dramatização do quotidiano, o burguês, atado às normas morais, nada cria e tudo reproduz.

Mas é papel da cultura "criar um animal manso e civilizado, um animal doméstico" (NIETZSCHE, 2016, p. 36), afinal de contas, as potencialidades, na medida em que desestruturam um pensamento preestabelecido, seguido à risca pelos "escravos", são forças que não interessam aos mantenedores do poder dominante. A arte, no final das contas, nunca foi bem quista desde que Platão expulsou os poetas da cidade. A autonomia é impensável para uma religião propagadora de virtudes ancoradas na renúncia da vida e em um livre-arbítrio que serve apenas para manter a ilusão de liberdade em sujeitos que pensam de maneira padronizada. Para Nietzsche, 
o indivíduo autônomo, além da moral (pois "autônomo" e "moral" se anulam), resumindo, o homem da vontade própria duradoura, independente, possuidor da prerrogativa da promessa - e nele uma consciência orgulhosa, palpitante em todos os músculos, do que afinal foi alcançado, e está corporificado -, a verdadeira consciência de força e liberdade, o sentimento de perfeição do ser humano em geral (2016, p. 52),

é o senhor, o homem livre, aquele que possui o domínio de si. O homem livre é "possuidor de uma longa e inquebrantável vontade, tem nessa posse o seu padrão de valores: olhando para os outros a partir de si ele honra ou despreza" (NIETZSCHE, 2016, p. 53). Ainda, com a mesma intensidade com que honra os que têm a soberania de si, a verdadeira autenticidade, o homem livre não se apieda dos espíritos débeis, escravos. Devo frisar, no entanto, que, para Nietzsche, ser senhor significa ter consciência das suas limitações, saber-se animal, falho. Distintamente da ideia de um além do humano, um santo negador da vida terrena, o homem livre é demasiado humano e sabe não ser nem sequer o centro de si mesmo. E é porque tem ciência das suas limitações que esse homem, ou esse "super-homem", como Zaratustra (NIETZSCHE, 2013), é sublime. A sabedoria aqui nasce da consciência de todas as limitações que envolvem o humano. Os valores próprios, que nada têm com as virtudes sacrossantas, só podem ser estabelecidos ao se desconstruir - e rechaçar - as verdades demasiadamente transcendentais impostas ao animal-homem. Trata-se de um princípio anárquico: o senhor responde unicamente à moral e aos princípios que ele próprio, em sua singularidade, estabeleceu.

O trabalho intelectual do senhor, no entanto, demanda a solidão dos hiperbóreos. Acerca da importante tarefa dos filósofos, Nietzsche alega: "veneramos a calma, o frio, o aristocrático, o longínquo, o passado e, de modo geral, tudo aquilo cujo aspecto não leve a alma a se defender e crispar-se - algo com que se possa falar sem elevar a voz" (2016, p. 
108-109). A ascese aqui encontra o seu significado não religioso na importância do trabalho do senhor, que é o de necessariamente pensar a vida e a sociedade, tarefa que não é possível aos escravos, aqueles que, na falta de um pensamento próprio, fracos e acovardados, alimentam o ressentimento frente ao mundo e aos outros homens.

É por meio do chamado "pathos da distância" que o senhor manterá um saudável afastamento do ressentimento e da nevrose comuns ao ideal ascético negador da vida. Dessa forma: "que os sadios permaneçam separados dos doentes, resguardados até da visão dos doentes, para não se confundirem com eles" (NIETZSCHE, 2016, p. 126). Afinal de contas, "os sadios são os fiadores do futuro, só eles estão empenhados no porvir do homem" (NIETZSCHE, 2016, p. 126). Superior à missão do escravo, que é a de manter o rechaço à vida em proveito das forças dominantes, a missão do senhor é a de pensar o hoje de maneira a desestabilizar as falaciosas regras morais.

É importante lembrar que, enquanto os fracos normalmente necessitam associarse, os fortes dissociam-se de qualquer gregarismo, afinal de contas, os senhores não se submetem a quaisquer organizações. Enquanto os fracos necessitam da igualdade para melhor se conformarem aos seus princípios negadores da vida, os senhores, porque necessariamente criam, só operam ao se diferenciarem, marcando assim o seu estilo próprio. Distintamente do asceta cristão, que cuida de si com a condição de renunciar a si mesmo, para Foucault (2014), o cuidado ético de si promovido pela ascese filosófica apresenta um fim em si mesmo, ou seja, algo que contribui para a felicidade do sujeito em vida, o que não se relaciona de maneira alguma com um cuidado para um fim após a morte. Tal arte, portanto, só é possível ao se romper com uma moral que tende a considerar o sujeito uma substância, portanto, passível de um certo e um errado muito dicotômicos e pouco múltiplos. 
Foucault (2014) define o sujeito como "práticas de sujeição". Não se trata de um sujeito platônico idêntico a si mesmo, afinal de contas, todos sabemos hoje que a forma não é idêntica a si. Trata-se antes de uma subjetividade "[...] que evidentemente não passa de uma das possibilidades dadas de organização de uma consciência de si" (FOUCAULT, 2014, p. 256). O sujeito ético, sempre cambiante, nunca igual a si mesmo, aplica ao seu cotidiano uma prática da liberdade. Para Foucault (2014), a ética é “[...] a prática da liberdade, a prática refletida da liberdade" (p. 261). A liberdade não é jamais dissociada da reflexão filosófica de si, da ascese filosófica. Ao passo que a ascese cristã, ressentida, por meio de um modus operandi que nega a vida, visa à renúncia de si, a ascese filosófica (que é a ascese dândi), intenta a autossuficiência, levando em consideração a exuberância das "práticas de sujeição".

A explicação de Foucault (2014) acerca do êthos na compreensão dos helenos é fundamental para essa ideia de dândi: "o êthos era a maneira de ser e a maneira de se conduzir. Era um modo de ser do sujeito e uma certa maneira de fazer, visível para os outros" (p. 264). O "belo êthos", portanto, para os gregos, era aquele que praticava "[...] a liberdade de uma certa maneira" (FOUCAULT, 2014, p. 264). O sujeito constituído, conforme Foucault, “[...] através das práticas de sujeição ou, de maneira mais autônoma, através de práticas de liberação, de liberdade, como na Antiguidade - a partir, obviamente, de um certo número de regras, de estilos, de convenções que podemos encontrar no meio cultural" (2014, p. 284), é necessariamente ético. O cuidado de si é um cuidado com o outro. Não é possível cuidar de si mesmo, operar um belo êthos, sem cuidar do outro, afinal de contas, como bem define Foucault, a matéria da ética é necessariamente "[...] a liberdade do sujeito e a relação com os outros" (2014, p. 279). Relacionado à "estética da existência" enquanto "obra de arte pessoal", o sujeito da 
Antiguidade, explica Foucault (2014), buscava uma "moral" e uma "ética da existência" ao afirmar a sua "liberdade", a fim de dar à sua vida "[...] certa forma na qual era possível se reconhecer, ser reconhecido pelos outros e na qual a própria posteridade podia encontrar um exemplo" (FOUCAULT, 2014, p. 283). Com o cristianismo, a busca por uma ética pessoal, ou obra de arte de si, tornou-se uma obediência a regras morais. Ora, é justamente ao sistema de regras morais que o dândi dos pampas resiste ao viver eticamente.

Para Baudelaire (2010), o dândi, esse ser que procura distinguir-se, sobressair-se em meio às subjetividades massificadas, é marcado pela revolta. No que diz respeito ao dândi dos pampas, não se trata necessariamente de uma "revolta metafísica", tal como define Albert Camus (2017) a atitude do dândi romântico. Não é porque não existe mais um Deus que o dândi, aqui, se revolta. O dândi dos pampas rebela-se contra a cultura da culpa, da expiação, aquela que nivela as subjetividades dos seus fiéis por meio de uma fraternidade enfraquecedora, pacífica. O dândi dos pampas, acima de tudo, rebela-se contra o status da espoliação próprio da América Latina. O matiz próprio do dândi dos pampas eu relaciono a um êthos revolucionário que resiste aos ditames de um Estado espoliador de si mesmo, um Estado que descuida dos seus filhos, que não foi pensado para triunfar. Inserido no contexto latino-americano, o dândi dos pampas revoluciona por meio da sua forma anárquica de vida. Encilhado sobre o seu cavalo, o dândi dos pampas pensa a si mesmo e o contexto onde está inserido de maneira a contestar as injustiças. Seu belo êthos é justamente um estilo de vida que, por meio das payadas, dá forma à miséria econômica denunciando-a.

Essencialmente solitário, essencialmente paradoxal, o dândi dos pampas canta a sua melancolia favorável à vida. Rei de si mesmo, detentor de uma ética singular, é 
necessário frisar que o dândi dos pampas não serve a nenhum patrão. O dândi é um contínuo pensador de si e do mundo. A forma de vida do dândi dos pampas é composta por versos inconformistas e de resistência. Para figurar o dândi dos pampas, analisarei duas payadas, uma do dândi argentino Yupanqui (1908-1992), outra do dândi brasileiro Braun (1924-1999). Ao aproximar ambos os trabalhos poéticos viso demarcar a característica principal de tal dândi: a anárquica insurreição do poeta filho de paisanos pampeanos.

\section{Yupanqui, o leão dos pampas}

Em Yupanqui o dândi recorda-se de quem foram seus antepassados, ato necessário para que se assuma quem se é. Não negando a sua origem crioula, o dândi mostra uma consciência de classe. O sangue camponês circula em suas veias. Assim: “Pero siempre he sido ansi: / Galopiador contra el viento. // Eso lo llevo en la sangre / Dende mi tatarabuelo / Gente de pata en el suelo. / Fueron mis antepasaos; / Criollos de cuatro provincias / Y con indios musturaos ${ }^{\mathrm{iii} \prime \prime}$. Não, o dândi dos pampas não é descendente de uma casta privilegiada, não é um oligarca. Descendente de criollos, o dândi assume-se tal como éiv , não negando, ressentido, suas origens. É justamente por não ser ressentido, amedrontado pelo patrão e desejoso de uma ascensão social mantenedora do status quo que o dândi dos pampas não aceita migalhas, e se rebela. “No sé si mi canto es lindo / O si saldrá medio triste; / Nunca fui zorzal, ni existe / Plumaje más ordinario. / Yo soy pájaro corsario / Que no conoce el alpiste", não há como manipular o dândi que galopa contra o vento, o eterno insurrecto dos pampas, o criollo revolucionário, pássaro corsário que não aceita alpistes. O rebelde não é jamais pássaro 
de jardim, tordo manso, presa fácil, o rebelde é predador, desenvolve uma forma de vida predatória, ou seja, uma forma de vida não inocente, passiva. Já na estrofe seguinte, o dândi-pássaro-corsário pode cantar, coroando seus belos versos: "Vuelo porque no me arrastro, / Que el arrastrar-se es la ruina; / Anido en árbol de espinas / Lo mesmo que en cordilleras / Sin escuchar las zonzeras / Del que vuela a lo gallina". Apesar das mutilações morais que o criollo necessariamente sofre por meio de uma vida tão miserável nos sentidos moral e econômico, o dândi dos pampas voa. A ruína do arrastar-se do sujeito derrotista que nada questiona e que a tudo diz amém é barrada pela árvore de espinhos que afasta o dândi dos acovardados, dos fracos, escravos ${ }^{v}$. O dândi dos pampas experiencia o real e por isso não se acovarda. A rebelião é a sua forma de vida, os seguintes versos assim o confirmam: "Es una falsa experiencia / Vivir tremblándole a todo. / Cada cual tiene su modo; / La rebelión es mi cencia".

O dândi dos pampas desbrava novas terras ao desnudar a realidade. Contínuo galopeador contra as forças contrárias, dominantes, é ele um flâneur que, desnudando-se em versos sinceros, afirma a si mesmo enquanto poeta revolucionário. Ao exprimir em versos a barbárie contra os oprimidos, reconhecendo-se criollo, o dândi dos pampas é um corpo político que, por meio de um estilo próprio, dá voz ao coletivo, reivindicando a liberdade. A forma heráldica das payadas e o estilo de vida que a ela está relacionada, o do payador revolucionário que por onde vai compõe riquezas poéticas, é prova desse dandismo. O dândi aqui vê todas as misérias da sua terra e disso faz seu canto. Tal qual o flâneur que, conforme Walter Benjamin (1989), faz seus versos do lixo que recolhe por onde passa, o dândi dos pampas canta as injustiças, denuncia-as. A dificuldade de emancipação e independência imposta pelos patrões é denunciada no seguinte excerto: 
“El trabajo es cosa buena, / Es lo mejor de la vida; / Pero la vida es perdida / Trabajando en campo ajeno".

A miséria imposta pelo capital é central no poema. Não se trata de uma miséria existencialista, trata-se acima de tudo de uma melancolia real, econômica. O dândi dos pampas sabe pelo que lutar. A miséria real é cantada de maneira crua: "Tal vez otro habrá rodao / Tanto como he rodao yo, / Y le juro, creameló, / Que he visto tanta pobreza, / Que yo pensé con tristeza: Diós por aquí no pasó". A exclamação que denuncia a melancolia econômica é expressa dessa forma: “iqué vida más despareja! Todo es ruindad y patraña.". A hostilidade e a desonestidade do mundo não são aceitos pelo sujeito ético de que é feito o dândi dos pampas, aquele que afronta a ideia naturalizada de um sistema de castas.

A payada é a forma de vida do dândi dos pampas. Ele vive para cantar o que vê, sente e pensa. O canto é a sua resistência à melancolia imposta dos pampas. Fica expresso que o canto encontra-se em todas as experiências de vida do dândi dos pampas nos seguintes versos: "Cuando sentí una alegría, / Cuando el dolor me golpió, / Cuando una duda mordió / Mi corazón de paisano, / Dende el fondo de los llanos / Vino un canto y me curó...". A saúde ética do dândi dos pampas é diferente da ética (sem saúde) do falso cantor, aquele que, volátil, utilizando-se de um mascaramento hipócrita, próprio do ressentido, não expressa quem é, não afirma a si mesmo e as suas ideias. O dândi dos pampas, de princípios distintos dos do ressentido, afirma a realidade porque a encontra em sua nudez. Aberto para o mundo e para os seus percalços, o dândi afirma a vida condenando os patrões e tudo o que impossibilita que uma terra floresça de forma mais justa. O êthos do dândi dos pampas não é um memento mori, como quer o imperialismo, mas uma força que pulsa vida. O dândi dos pampas é o poeta não amado pelo patronato, 
é o contestador. Estabelecendo a distinção entre o poeta que não incomoda e o poeta revolucionário, o valente que faz da sua vida uma canção de protesto expressa o primeiro da seguinte maneira: "Si uno pulsa la guitarra / Pa cantar coplas de amor, / De potros, de domador, / De la sierra y las estrellas, / Dicen: iqué cosa más bella! / iSi canta que es un primor!". Entretanto, frente ao poeta revolucionário, que é o próprio dândi dos pampas, aquele que, sobre o seu cavalo, recolhe por onde vai o material poético que lhe serve de combustível para a sua forma de vida revolucionária, o patronato, obviamente, comportase de outro modo: "Pero si uno, como fierro, / Por ahí se larga opinando, / El pobre se va acercando / Con las orejas alertas, / Y el rico vicha la puerta / Y se aleja reculando". A arte do dândi dos pampas é feita de contestações. O dândi quer incomodar. Ele não se vende ao patronato. Devo aqui lembrar o que diz Nietzsche acerca do "grande estilo" (2017): é grande estilo aquele que não deseja agradar. Afirmar a si mesmo é o maior dos princípios do dândi dos pampas. Por meio de um ritmo singular que sorri em belas coplas tal dândi canta a sua terra e a si mesmo.

O canto do dândi dos pampas, devo destacar, é dado ao "pobre", não ao patrão. "Yo vengo de muy abajo, / Y muy arriba no estoy. / Al pobre mi canto doy / Y así lo paso cantando, / Porque estoy en mi elemento / Y ahí valgo por lo que soy", é dessa forma que o dândi dos pampas afirma a sua ética verdadeira, conforme àquilo em que acredita e àquilo que ele é. A preocupação do dândi dos pampas com a vida está acima de qualquer ouro. Como o próprio dândi expressa: "Yo no traiciono a los míos / Por palmas ni patacones". Afinal de contas, "Siempre canté estremecido / Las penas del paisanaje, / La explotación y el ultraje / De mis hermanos queridos.". O dândi não aceita o ultraje da liberdade dos explorados. Quando encilhado, o dândi afirma ser "bagual". O "cantor" intelectual dos pampas [...] debe ser libre / Pa desarrollar su cencia. / Sin buscar la 
convenencia / Ni alistarse con padrinos". O verdadeiro cantor, que é o dândi dos pampas, sustenta a sua ética, uma ética que resiste ao sistema de espoliação ao não se deixar vender conforme a conveniência. A arte de si, o cuidado ético de si não permite aquilo que contradiz os seus princípios. O dândi dos pampas não canta "por orden del patrón".

Devo frisar que a ética do dândi dos pampas é movimento. Tal qual Don Quijote, ele sai pelo mundo sobre o seu cavalo à cata de experiências para expressá-las em seu canto de denúncia e resistência. Quanto ao seu movimento pelo mundo: "Yo he caminao por el mundo, / He cruzao tierras y mares / Sin frontera que me pare / Y en cualsquiera guarida / Yo he cantao, itierra querida!, / Tus dichas y tus pesares". Flanando entre as formas de existir e as experiências de si, o dândi dos pampas faz mel da sua amargura. Há melancolia, mas essa não basta para o dândi. Zaratustra é aquele que, por ter sofrido demais, compõe os mais belos versos ao rir-se do "espírito do Pesadume" (NIETZSCHE, 2013). Assim nos fala o dândi dos pampas: “Dicen que no tienem canto / Los ríos que son profundos / Mas yo aprendí en este mundo / Qu'el que tiene mas hondura / Canta mejor por ser hondo / Y hace miel de su amargura".

É porque esquece-se de si que o dândi dos pampas dá forma a tudo o que vê e sente em seu galopar. O dândi dos pampas compõe-se de mundo. Os princípios férreos do dândi dos pampas, favoráveis à vida e à dignidade humana, voltam-se, peleiam, resistem contra os valores do patronato. Os valores próprios do dândi ofendem os interesses dos estancieiros devoradores de vidas. Aqui não é Chronos quem devora os próprios filhos. Há a miséria da fome antes da existencial. O dândi dos pampas é o poema vivo que, ao sair pelo mundo acusando as injustiças, resiste ao lado dos seus, os criollos. "Guarida no necessito / Yo se dormir al sereno": o dândi dos pampas não possui lugar, ele é composto por seu movimento poético regido pelo cuidado com a vida. Afinal de contas, 
"Siempre hay alguna tapera / En la falda de una sierra / Y mientras siga esta guerra / De injusticias para mi, / Yo he de pensar desde allí / Canciones para mi tierra". Ainda: "Y aunque me quiten la vida / O engrillen mi libertá / Y aunque chamusquen quizá / Mi guitarra en los fogones, / Han de vivir mis canciones / En l'alma de los demás". Leão dos pampas, o dândi só o é porque faz da sua vida uma questão política. A sua ética reclama por uma liberdade primária. Não há renúncia ou pessimismo. Aqui as questões existenciais dizem respeito a uma falta real.

\section{Braun, o tigre charrua}

O dândi dos pampas recebe outra coloração em "Payada", de Braun, outra forma para a busca pela liberdade. Quem é esse dândi senão a personificação da história? A liberdade aqui está atada ao conhecimento da história. É pelo testemunho histórico que o rebelde faz a sua denúncia. O herói cuja matéria é o tempo histórico denuncia as chagas que se deram ao longo do tempo e que nunca deverão deixar de ser lembradas, a fim de que se compreenda o presente. Já na primeira estrofe, o dândi afirma o seu anseio por liberdade ao fazer-se história:

Raízes, tronco, ramagem... Ramagem, tronco, raiz... / Abriu-se uma cicatriz de onde brotei na paisagem... / O tempo me fez mensagem que os ventos pampas dirigem, / Dos anseios que me afligem de transplantar horizontes, / Buscando o rumor das fontes para beber água na origem. ${ }^{\text {vi }}$ 
A musicalidade dos versos expressa bem a exuberância das fontes buscada pelo poeta. A "Liberdade", enquanto "estrela guia" do poeta, é evidenciada em toda a payada, em especial na segunda estrofe:

Sobre o lombo da distância, de paragem em paragem, / Fui repontando a mensagem de bárbara ressonância, / Fazendo pátria na infância porque precisei fazê-la, / E a Liberdade, sinuela, sempre foi a estrela guia / Que o meu olhar perseguia como quem busca uma estrela.

O poeta toma a liberdade como condutora do seu porvir. O seu canto é dirigido a ela. É a liberdade que o dândi dos pampas, homem-histórico que é, persegue. A história do Rio Grande do Sul é, assim, cantada pelo dândi dos pampas tendo como leitmotiv tal busca que é uma constante em todo o poema. A saga inicia-se na terceira estrofe, quando o poeta canta:

Pensei chegar alcançá-la, no estágio de índio rude, / Mas nunca na plenitude, porque essa deusa baguala / Que aos andrajos embuçala, nunca ninguém alcançou, / Bisneto nem bisavô, nos entreveros mais brutos, / Labareda de minutos que o vento sempre apagou.

Sempre efêmera, nunca em sua totalidade, a liberdade foge das mãos do poeta.

E então:

Primeiro era o campo aberto, descampado, sem divisas... / Com fronteiras imprecisas, mundo sem longe nem perto... / Eu era o índio liberto, barbaresco e peleador / Rei de mim mesmo, senhor da natureza selvagem, / A religião da coragem e o sol de bronze na cor, 
figurado como soldado da liberdade, o dândi dos pampas tem por religião a coragem e o elemento solar gravado na pele. A origem mítica é aqui gloriosa, afinal de contas, nessa fase o índio era liberto, rei de si mesmo e, portanto, bravo e nobre.

Peleador, o homem-histórico que visa a liberdade assim expressa os seus combates:

Mais tarde veio mais gente às minhas terras campeiras... / A falange das bandeiras, impiedosa e inclemente... / Me levantei de repente e as tribos se levantaram... / As várzeas se ensangüentaram, elas que eram verdejantes, / Mas eu venci os bandeirantes, que nunca mais retornaram!

E mais:

[...] vieram os lusos, os negros, os castelhanos, / E nos pagos campejanos, novas normas, novos usos... / As violências e os abusos da Ibéria, Castela e Lácio / Que rasgaram o prefácio e mataram as plegárias / E as ânsias comunitárias dos irmãos de Santo Inácio.

A importância da denúncia histórica é afirmada pelo dândi dos pampas na estrofe seguinte: "Se a História não os condena, a mancha nunca se apaga! / A opressão jamais indaga na sua ambição mesquinha, / Era meu tudo o que tinha, era meu tudo o que havia / E eu morri porque dizia que aquela terra era minha!". As terras indígenas usurpadas pelo homem branco e a memória dos seus verdadeiros donos reivindicam a verdade por meio da canção do dândi dos pampas. Porta-voz dos historicamente injustiçados, tendo a liberdade como estrela-guia, o dândi dos pampas afirma o que foi ao pensar no que será. Há que se condenar o que deve ser diverso no futuro: a amarga miséria dos injustiçados 
devido a forças econômicas maiores. Consciente das suas origens, é pelo fim da opressão que o rebelde dos pampas peleia em versos. $O$ dândi dos pampas bebe água da origem para marcar a sua resistência em poesia.

Em resistência à injustiça feita contra os verdadeiros donos das terras, a força da "raça gaudéria", aquela que resiste às opressões históricas - raça do dândi dos pampas -, é afirmada da seguinte maneira:

Mas o eterno não morre, porque permaneço vivo... / No lampejo primitivo de cada fato que ocorre / O meu sangue rubro corre na velha raça gaudéria, / Corcoveando em cada artéria pela miscigenação / $\mathrm{Na}$ bárbara transfusão com os andarengos da Ibéria.

De "raça" miscigenada, o gaudério é o verdadeiro dândi dos pampas. Mas quem é o dândi dos pampas? "Sou o brasedo que ficou e aceso permaneceu, / Sou o gaúcho que cresceu junto aos fortins de combate / E já estava tomando mate quando a pátria amanheceu!!!”. Bravo, de sangue guerreiro,

[...] crescendo ao relento, criado longe do pai, / Junto ao mar doce - o Uruguai -, o rio do meu nascimento, / Soldado sem regimento no quartel da imensidade... / Um dia me deu vontade, deixei crescer toda a crina / E me amasiei com uma china que chamei de Liberdade!

De cabelos longos, soldado sem quartel, o dândi dos pampas esbanja vontade de liberdade por meio do seu cantar, a sua forma de vida. Ao invés de se conformar com uma melancolia entreguista, o gaúcho-dândi exubera vida e virilidade por meio de um estilo de vida feito do cantar a sua terra. Enamorada de Liberdade, a força de vida, não desvinculada do grito da justiça, é mais forte do que o abatimento e o pessimismo. Não há como deixar de reclamar justiça ao amasiar-se com Liberdade. 
Ora, quem é o dândi dos pampas? O poeta expressa o mito de si mesmo da seguinte maneira: “Poeta, cantor e guerreiro da América que nascia / Na bendita teimosia de continuar brasileiro!!!”, afinal de contas, "A pátria é minha família! Não há Brasil sem Rio Grande / E nem tirano que mande na alma de um Farroupilha!". O dândi dos pampas é o inconformado, o revolucionário, o homem de espírito nobre, peleador, aquele que se desmembra em algo maior, coletivo. “Hoje, tempo de mudar, meu coração continua / O mesmo tigre charrua das andanças do passado. / Sempre de pingo ensilhado [sic], bombeando pampa e coxilha": o dândi dos pampas é o eterno inconformado, o contínuo furacão que incomoda os estancieiros. Afinal de contas, quem é o dândi dos pampas senão o intelectual que não "agrada" ao denunciar em payadas a sangria da história latinoamericana? Vale lembrar o papel político do intelectual expresso por Foucault (2014): “[...] o papel de um intelectual é mudar alguma coisa no pensamento das pessoas." (p. 288). Qual o papel de um artista-intelectual, um inconformado das coxilhas, qual o papel do dândi dos pampas senão afirmar a luz da liberdade?

\section{Conclusão}

O dândi dos pampas, homem-histórico que se revolta contra o patronato por meio de suas canções e forma de vida, é um símbolo de resistência entre os gauchos. O dândi dos pampas só pode ser sensível à medida que também calculista. Não um calculismo burguês, que se volta ao lucro, mas o cálculo de uma arte que sabe em que politicamente - a sua forma está implicada. Não se trata de um romântico que sucumbe às paixões, um entreguista da sua "economia psíquica" a outrem (o patrão). Feito da massa da história, é ao experienciar-se no mundo que o dândi dos pampas compõe 
formas em versos. Força de vida, êthos que exubera em versos, o dândi dos pampas é combustível para a revolução. O dândi dos pampas revoluciona com sua arte ao revolucionar-se como sujeito ético com princípios que garantem poder e singularidade ao seu verbo.

O que está em discussão aqui é o ser, não o ter. A flânerie pampeana, enquanto movimento poético que dá forma a tudo o que o artista vê e sente garante a riqueza de um êthos revoltado, insubmisso. Eis a forma de uma vida bela, uma vida estetizada cujo movimento generoso - de olhar voltado para o coletivo, pois que toda a ética está implicada no coletivo - garante a permanência da sua arte enquanto arte de resistência, beleza que não quer agradar. O dândi dos pampas, ao fim e ao cabo, é o verdadeiro senhor em terras de senhores de terras, aquele cujos princípios marcados em versos revelam o artista revolucionário que encontra na poesia uma voz heráldica de denúncia.

\section{Referências}

AGAMBEN, Giorgio. Profanações. São Paulo: Boitempo, 2007.

BAUDELAIRE, Charles. O pintor da vida moderna. Belo Horizonte: Autêntica, 2010.

BENJAMIN, Walter. Charles Baudelaire: um lírico no auge do capitalismo. São Paulo: Brasiliense, 1989.

BRAUN, Jayme Caetano. Payada. Disponível em: <https://www.vagalume.com.br/jaymeca etano-braun/payada.html>. Acesso em: 20 jul. 2018.

CAMUS, Albert. O homem revoltado. Rio de Janeiro: BestBolso, 2017.

FOUCAULT, Michel. Ditos \& escritos V: ética, sexualidade, política. 3. ed. Rio de Janeiro: Forense Universitária, 2014.

NIETZSCHE, Friedrich. Genealogia da moral. Rio de Janeiro: BestBolso, 2016. 
SCHIFFER, Daniel Salvatore. Manifeste dandy. Paris: François Bourin Editeur, 2012.

YUPANQUI, Atahualpa. Coplas del payador perseguido. Disponível em: < BRAUN, Jayme Caetano. Payada. Disponível em: <https://www.vagalume.com.br/jayme-ca etanobraun/payada.html>. Acesso em: 20 jul. 2018.

Recebido em 31 de julho de 2018.

Aceite em 26 de fevereiro de 2019.

\begin{abstract}
' Daniel Salvatore Schiffer (2012), em sua teoria sobre o dandismo, define o dândi como o intelectual cosmopolita, relacionando o dândi ao flâneur metropolitano.

"Apesar de Nietzsche (2016) usar o termo "indivíduo", opto pela utilização do termo "sujeito", já que melhor se conforma com a ideia que faço de sujeito para o dândi dos pampas, ancorada ao sujeito de Foucault (2014), estudioso de Nietzsche, que será especificada mais tarde no artigo. Minha concepção de sujeito concorda igualmente com a de Giorgio Agamben quando explica, em Profanações (2007), o que chama "ser especial": "[...] ser especial não significa o indivíduo, identificado por esta ou aquela qualidade que the pertence de modo exclusivo. Significa, pelo contrário, ser qualquer um, a saber, um ser tal que é indiferente e genericamente cada uma de suas qualidades, que adere a elas sem deixar que nenhuma delas o identifique" (p. 53). Ao contrário de indivíduo, sujeito é, desse modo, insubstancial. De maneira oposta às críticas feitas a Nietzsche em relação ao seu "pathos da distância", não compreendo a solidão como modo de vida defendido pelo filósofo como uma espécie de individualismo, mas uma forma de vida, tal qual as muitas possíveis, preocupada com o cuidado de si e do outro, portanto, ética.
\end{abstract}

iii A letra completa se encontra no seguinte link: <https://www.vagalume.com.br/atahualpayupanqui/coplas-del-p ayador-perseguido.html>.

iv Outro exemplo dessa consciência de classe é quando o dândi se afirma gaucho: "Si alguien me dice señor, / Agradezco el homenaje; / Mas soy gaucho entre gauchaje / Y soy nada entre los sabios."

"O dândi dos pampas afirma ainda a sua superioridade aos escravos: "Yo soy de los del montón, / No soy flor de invernadero".

vi A letra completa se encontra no seguinte link: <https://www.vagalume.com.br/jayme-caetano-brau $\mathrm{n} /$ payada.html>. 